\title{
REGALÍA DE LAS AGUAS PÚBLICAS Y DOMINIO PÚBLICO HIDRÁULICO
}

\author{
Antonio Gil Olcina \\ Instituto Interuniversitario de Geografía. Universidad de Alicante
}

\section{RESUMEN}

Hasta la promulgación de la Ley de 3 de agosto de 1866 sobre dominio, uso y aprovechamiento de aguas, en la España Peninsular el derecho sobre esta materia se adscribía a dos grandes tradiciones jurídicas: castellana y valenciana. Esta última, que informaría la susodicha norma, primer código español y europeo al respecto, acabaría por prevalecer, merced al destacado protagonismo en la redacción de aquélla del prestigio jurista Antonio Rodríguez de Cepeda, catedrático de Derecho Administrativo de la Universidad de Valencia, Decano de la Facultad de Derecho y del Colegio de Abogados, profundo conocedor del derecho de aguas valenciano.

En la distinción del derecho foral valenciano entre aguas públicas y privadas, concepto el primero de contenido notoriamente más amplio que en las Partidas, quedaban sometidas aquéllas a la titularidad y dominio del Real Patrimonio. Dicha regalía sobre aguas públicas se halla en los orígenes del dominio público hidráulico que, ampliado y enriquecido por la Ley 29/1985, regula el modificado Texto Refundido de la Ley de Aguas.

Palabras clave: Derecho foral valenciano, regalía sobre aguas públicas, dominio público hidráulico.

\begin{abstract}
Before the enactment of the Law dated August 3rd 1866 concerning the domain, use and exploitation of water, rights regarding this issue were subject to the two major legal traditions in Peninsular Spain at that time, namely the Castilian and the Valencian systems. The latter, which would form the basis of the above-mentioned law, was the first Spanish and European legal code to deal with the subject. It largely prevailed due to the important role played in drafting it by the renowned jurist Antonio Rodríguez de Cepeda, Professor of Administrative Law at the University of Valencia, Dean of the Faculty of Law and the Bar Association and a leading expert on Valencian water law.

In the distinction made by Valencian autonomous law between public and private waters, where the former concept is markedly broader in content than in the Partidas (the body of common laws drawn up by Alfonso X), these were subject to the ownership and domain of Royal Patrimony. Said prerogative over public waters is found in the origin
\end{abstract}


of public hydraulic domain which, expanded and enriched by Law 29/1985, regulates the modified Revised Text of the Law of Waters.

Keywords: Valencian autonomous law, prerogative over public waters, public hydraulic domain.

Además de rico derecho consuetudinario y abundantes particularismos, alguno tan trascendente como la privatización de las aguas claras perennes o vivas de los ríos-ramblas (Amadorio, Monnegre, Vinalopó, Mula, Guadalentín, Bajo Almanzora) en los regadíos deficitarios del Sureste Ibérico ${ }^{1}$; a comienzos del ochocientos, en el ámbito de la España Peninsular, subsistían dos grandes tradiciones jurídicas en materia de aguas: una, encarnada por los antiguos reinos de la Corona de Castilla, restringía la titularidad pública de las aguas fluyentes a los ríos navegables o flotables, es decir, a los más caudalosos, mientras en las restantes corrientes de agua primaba el derecho de uso por los ribereños, a tenor del viejo principio jurídico de utilización de las mismas por aquéllos usque ad medium filium aquae. La otra, vigente en los territorios que, hasta el decreto abolicionista de 29 de junio de 1707 , luego de la batalla de Almansa, acaecida el 25 de abril de ese mismo año, habían constituido estados forales de la Corona de Aragón, y muy especialmente en la provincia-reino de Valencia, poseedora de una excepcional y muy arraigada cultura en el aprovechamiento del agua para riego y como fuerza motriz, hacía depender del Real Patrimonio el empleo de aquélla en ambos usos; la necesaria autorización se producía a través de la enajenación o concesión de la regalía correspondiente, en forma de derecho exclusivo, privativo y prohibitivo a los señores jurisdiccionales, sin que faltasen tampoco meros establecimientos del dominio útil, con imposición de censos enfitéuticos, para la instalación de molinos u otros artefactos hidráulicos, como batanes, martinetes o barcas de paso; en realengo, fue ésta la figura jurídica usual (cens catalán, treudo aragonés y establiment valenciano). Para la construcción de azudes, se requería la autorización o privilegio regio, con el ejemplo prototípico que proporciona la prolongación de la Real Acequia de Alcira por el duque de Híjar y, entre otros muchos títulos, barón de Sollana en la segunda mitad del siglo XVIII. En efecto, el privilegio otorgado el 16 de enero de 1404, sería invocado, en 1771, por don Pedro Alcántara Fadrique Fernández de Híjar Silva Abarca de Bolea Jiménez de Urrea, Portugal, Portocarrero, Mendoza y Luna, duque de Híjar, marqués de Oraní y, en el reino de Valencia, titular de las baronías de Monóvar y Sollana, «...en su consecuencia se le concedió permiso por el Gobierno para prolongar el canal desde Algemesí en adelante, abriendo la nueva acequia que hoy se llama del Proyecto...» (MADOZ, 1847, I, pág. 449); el azud de Antella fue enteramente rehecho, con mayores altura y fortaleza, para derivar más caudal, al tiempo que se añadió una tercera compuerta («Para tomar pues, mayor porción de agua del Júcar, fue por lo que colocó el duque la compuerta que le corresponde»).

En el segundo tercio del siglo XIX, la promulgación del Real Decreto de 29 de abril de 1860 , sobre prioridad de usos para la concesión de aguas públicas, y de la Ley de 3 de agosto de 1866 relativa al dominio, uso y aprovechamiento del agua, primer código español y europeo en la materia, generalizaron la expresada tradición jurídica valenciana, al declarar públicas las aguas corrientes. Sin embargo, la trayectoria hasta ese momento dista de ser rectilínea, ya que, hasta entonces, no faltaron disposiciones fundadas en el derecho de los ribereños, sobre todo el Real Decreto de 3 de mayo de 1834 concerniente a caza y pesca. Esta norma atribuyó el aprovechamiento de la pesca a los ribereños, ya se tratase de par-

1 GIL OLCINA, A.: La propiedad de aguas perennes en el Sureste Ibérico, Alicante, Universidad de Alicante, 1993, 191 págs. 
ticulares o ayuntamientos, «hasta la mitad de la corriente», con las limitaciones inherentes a la servidumbre de navegación.

\section{Aguas públicas y privadas en el reino de Valencia}

Una Real Orden de 13 de abril de 1777 dispuso, entre otros extremos, que «se recogiesen y recopilasen todos los fueros, privilegios y actos de corte relativos á los derechos del Real Patrimonio, y a la jurisdicción que correspondia al Intendente en el concepto de Bayle general; así mismo todas las órdenes antiguas y modernas, y las decisiones, privilegios y executorias, con las demas noticias que pudiesen contribuir á poner en claro dichos derechos y jurisdiccion»; y, acto seguido, dicha tarea fue confiada al Intendente Don Vicente Branchat. Fruto de la referida comisión resultó el monumental Tratado de los derechos y regalías que corresponden al Real Patrimonio en el Reino de Valencia, distribuido en tres gruesos volúmenes y publicado en $1784^{2}$.

En el Capítulo VI, concerniente al «Derecho que corresponde á S.M. en todos los rios y aguas públicas del Reyno de Valencia, y en las particulares que nacen en los territorios de los pueblos de realengo: y de la jurisdicción que en su razon pertenece al Intendente como subrogado en el lugar y facultades del antiguo Bayle general», Branchat señala que «las aguas se dividen principalmente en públicas y privadas. En la primera clase se comprenden los rios navegables y no navegables, y todas las que tienen perenne y contínuo curso, aunque nazcan en terreno de dueño particular. Y las privadas se llaman aquellas, que teniendo orígen en territorio de privado dominio, por su corta cantidad, ó por no ser perenes, no pueden utilizarse en utilidad pública. Las primeras siempre se han considerado regalía del Príncipe, que puede disponer de ellas á su arbitrio, y ningun otro sin Real licencia. Pero las segundas son del dueño del campo donde nacen, que puede darlas el destino que le sea más útil.

2. En el Reyno de Valencia todas las aguas, así públicas como privadas, pertenecieron al Rey Don Jayme I por título de conquista, el qual en uso de su dominio agració á los Prelados y Ricos-Hombres con las que nacian y pasaban por los términos de los pueblos de que les hizo donacion, conservando en la Corona la regalía de los rios y aguas públicas, y las privadas de los términos realengos: y en todas ellas ejercieron y han ejercido siempre, así el Rey Conquistador como sus sucesores, una absoluta autoridad por sí, y por medio de los Bayles generales,...

3. En quanto á los rios públicos, son muchos los testimonios que acreditan la suprema facultad con que los Reyes, usando del absoluto derecho que sobre ellos tienen, han dispuesto de sus aguas, así para el beneficio del comun como para el de los particulares...»³; y, en apoyo de esta aseveración, aduce Branchat una serie de privilegios y decisiones reales, relativas primordialmente a flotación de maderas, edificación de azudes, toma y derivación de aguas, partición de módulos fluviales, trasvase de aguas, instalación de molinos hidráulicos, construcción de puentes, explotación de barcas, y licencias de pesca.

Por su gran importancia y carácter conflictivo, la flotación de maderas mereció, desde el primer momento la mayor atención; así, Jaime I, por privilegio dado en Alcira, el 30 de enero de 1267, «concedió facultad para que cualquiera pudiese conducir la madera que cortase en los lugares del Reyno de Valencia por los ríos Guadalaviar y Xúcar, franca y libremente, y sin contradicción». Ante la reclamación de la ciudad de Valencia por las dificultades que creaban al tráfico de maderadas por el Turia vecinos de Chelva, Jaime II

2 BRANCHAT, V.: Tratado de los derechos y regalías que corresponden al Real Patrimonio en el Reino de Valencia, Valencia, 1784, 3 vols.

3 BRANCHAT, Op. cit., cap. VI, págs. 295-296. 
ordenó, a 1 de junio de 1314, que el Teniente de Procurador General del Reino «hiciese levantar todo embargo y detención»; y el propio monarca, por privilegio de 1 de mayo de 1321, «habiendo entendido que en el lugar de Cofrentes se hacia pagar diezmo y peaje por la madera que se conducia de los montes de Castilla por los rios Cabriel y Xúcar para el Reyno de Valencia (lo que era contra el tenor de los privilegios concedidos por sus antecesores), mandó al Bayle general y á los colectores de peage, guardasen dichos privilegios, y no causaren molestia alguna á los conductores por dicha razon...»Y, en este mismo orden de cosas, el 10 de noviembre de 1360, Pedro II, ante la queja de la ciudad de Valencia sobre que dueños de castillos y lugares en las riberas del Mijares «impedian el tránsito de las maderas, que algunos Mercaderes habian cortado en término de Aragon, y conducian por él, queriendo cobrar cierto derecho por razon del pasage, no obstante que los conductores ofrecian pagar todos los daños que pudiesen causar en las riberas ó azudes de dichos pueblos,... mandó al Teniente general de Gobernador del Reyno compeliese á los dueños de dichos pueblos, á que dexasen pasar libremente las maderas por sus términos, pagándoles solo los daños que causaren por razón del tránsito». Décadas después, en el reinado de Alfonso III de Valencia y V de Aragón, las villas de Castellón, Burriana y Almazora representaron al Rey Juan de Navarra, Lugarteniente General del Reino, que «Pedro de la Spasa y Sancho Canon pretendian conducir una considerable porcion de madera y leña por el rio Mijares, con grande perjuicio de las mismas: pues siendo poca el agua, no podia llegar la madera al mar sin considerable daño de las presas y azudes, que en virtud de Reales permisos habian hecho en el mismo rio para el riego de las tierras de dichos términos». Un real privilegio de 8 de enero de 1433 ordenó a dichos asentadores que «baxo pena de mil florines de oro se abstuviesen de conducir madera por dicho rio mas allá de las represas o azudes, que tenian construidas dichos pueblos en virtud de licencias Reales para el riego de sus tierras» ${ }^{4}$.

Como se ve, la anterior referencia reitera que las presas y azudes habían sido levantados con licencia regia. Asunto éste de la mayor trascendencia, al punto que Jaime II, el 1 de agosto de 1318, ordenó al Procurador General del Reino que «hiciese demoler sumariamente y sin figura de juicio las nuevas azudes y acequias, que habian hecho ó ensanchado los dueños territoriales que tenian pueblos inmediatos á la orilla del rio Guadalaviar, reponiendo las cosas en el estado que tenian ántes...». En 1573, ante la pretensión de algunos vecinos de Alcira de «hacer azudes o represas en el rio de los Ojos (lo que de ningun modo podia practicarse sin expresa Real licencia, aun en lugares de realengo, por ser los rios regalia propia de S.M.), mandó el Bayle general se publicase pregon en dicha villa y demas parages donde fuese necesario, para que ninguna persona pudiera hacer azudes en dicho rio sin su licencia, baxo la pena de ser arruinadas y de mil ducados aplicaderos al Real Patrimonio...». Y, en esta misma línea, «el año 1690 representó la villa de Cullera al Rey Don Carlos II, que por el mes de Abril del año 1686 habia concedido á la misma el uso del cano llamado vulgarmente del Rey, que S.M. tenia en la ribera del rio Xúcar, entre tanto que la villa reedificaba el cano, y pedazo de acequia que se habia llevado el rio; y que por no tener medios para dicha obra, suplicaba le hiciese merced del uso perpetuo y dominio útil que le habia concedido temporalmente: cuya gracia le dispensó S.M. con la pension anua de treinta reales, y la obligación de hacer todas las obras que necesitase dicho cano para su conservación, reservando para sí y sus sucesores los Reyes de Aragón el dominio directo, y demas derecho enfitéuticos que le pertenecian en dicho cano, y la facultad de reintegrar á la Corona del dominio útil quando necesitase de él la Real Hacienda, lo que pudiese efectuar sin citacion ni intervencion de la villa: 
y que si al tiempo de la reintegracion hubiese hecho algunas obras y mejoras en dicho cano, no tuviese obligación de pagarlas, $\ldots \gg^{5}$.

Hace asimismo alusión Branchat a la autorización de proyectos para derivar aguas del Júcar o de redistribución de las concedidas en el Turia. Así, Juan I, por privilegio dado en Tortosa, el 15 de noviembre de 1393, «concedió á los Jurados y buenos hombres de Valencia, que siempre que quisieren pudiesen tomar agua del rio Xúcar en el término de Tous, y conducirla al rio Turia ó Guadalaviar para el riego de sus heredades y demas usos, con tal que á los dueños de las tierras, por donde hubiese de pasar, se les satisficiesen todos los daños y perjuicios. El Rey Don Martin por otro (privilegio) que expidio en 16 de Enero del año 1404, tambien dio facultad á los vecinos de dicha Ciudad, y á los dueños de los lugares de Alginet, Sollana, Trullás, Alcahecía, Torre de Romaní, Almuzáfes, Benifayó, Espioca, Silla y Picacent, Alcocer, Beniparrell, Albal y Catarroja, para que pudiesen tomar del rio Xúcar toda el agua que necesitasen por el azud de la Acequia Real de Alzira, ensanchándola y profundizándola á este fin en los parages que les pareciese necesario, con tal que fuese sin perjuicio de los vecinos de la villa de Alzira y demas regantes. Y en 14 de Junio del año 1419 dió licencia el Bayle general á Juan Dorta Ciudadano, para que hiciese un azud en el rio Guadalviar, despues del de Rovella, y hasta la torre de Santa Catalina, y que edificase molino ó molinos, y hiciese acequias para conducir las aguas, concediéndole en enfiteusis el azud, molinos, acequias y almenaras todo á censo anuo de diez sueldos, y con los derechos de luismo, fadiga y demas enfiteuticales».

Con relación a los renglones anteriores, y referencia a molinos, barcas de paso, y pesca, puentes flotantes, como el famoso de Cullera, sobre el Júcar, así como puentes fijos de argamasa y cantería, encarece Branchat que «no solo era propio de la soberanía el disponer de las aguas de los rios, si que tambien correspondia á la misma el dar licencia para tener barcos, pescar en ellos, y construir puentes para su tránsito: cuya facultad han ejercido por sí, y por medio de sus Bayles generales, al igual que todos los demas actos pertenecientes al supremo dominio de los rios y sus cauces. Pues consta que en el año de 1377 se publicó bando de órden del Bayle general para que ninguno entrase con barco en el rio Guadalaviar. En el de 1424 el Rey Don Alfonso III concedió en enfiteusis á Bernardo Besaldú el derecho de tener barcos en el rio Guadalaviar desde el lugar de Paterna hasta el mar, con el censo de un morabatin de oro por cada barco que tuviese para el paso de dicho rio. Y ... Juan II en 21 de Enero de 1460 estableció y concedió en enfiteusis á Luis de Naguera el derecho de tener un barco en el rio Xúcar junto al molino que poseía en término de la Baronía de Corbera y de Rióla, con el censo anuo de cinco sueldos». En 1684, un recurso del conde de Almenara, titular de la baronía de Antella, contra una decisión del Procurador Patrimonial, que le ordenaba retirar del Júcar una barca de paso, fue desestimado con imposición de costas al recurrente, fundándose la sentencia «en que el rio Xúcar era regalía, que llevaba anexa la prohibicion de tener barcos sin Real licencia: y que aunque atendido el derecho comun, en la donacion de los pueblos se entendian comprehendidos los rios, esto no tenia lugar por derecho foral, ántes bien estaba establecido por expreso privilegio, que solo el Rey tenia el dominio de dicho rio, con exclusion de los dueños que poseían territorios cerca de su ribera, á los quales solamente les correspondia aquello que por fuero estaba concedido para el uso público: y que no habiendo manifestado el dueño de Antella Real privilegio á su favor para tener dicho barco en el rio, era conseqüente su prohibicion. Y por idéntica razón, el conde del Real suplicó y obtuvo privilegio de Felipe V, en 1703, para construir un puente sobre el Júcar, entre Millares y Dos Aguas, «con facultad de cobrar el derecho de pasage o pontage, solo hasta que se reintegrase de lo gastado en la fábrica y conservacion

5 BRANCHAT, Op. cit., cap. VI, págs. 303-305. 
del puente, con reserva de acordar lo conveniente despues de reembolsado el caudal que hubiere expendido...» ${ }^{6}$.

En suma, Branchat concluía y subrayaba que «los rios públicos del Reyno de Valencia siempre se han considerado regalía del Rey», entendiendo, además, que por aguas públicas se tenían también «aquellas que tienen perene curso por barrancos ó acequias»; y, en cuanto a las aguas que nacen o pasan por términos de realengo, «como en estos tiene el Rey todo el dominio territorial y campal, le es indisputable la facultad de disponer de ellas á su arbitrio, de la que han usado sin interrupcion desde el tiempo de la conquista, estableciéndolas en enfiteusis, ó bien para fábricas de molinos, ó para riego de las tierras: y en los casos en que se ha formado juicio contencioso, ó bien sobre la concesión de las aguas, ó sobre mantener á algunos interesados en el derecho de ellas, siempre han conocido los Intendentes en virtud de su privativa jurisdiccion, quedando á cargo de la Justicia ordinaria los pleytos sobre penas y daños, sobre division, reivindicacion y otros de esta especie» ${ }^{7}$.

A los efectos que ahora interesan, y en síntesis, es de resaltar la notoria coincidencia entre la regalía de aguas públicas contemplada y delimitada, en el reino de Valencia, por Branchat y el dominio público hidráulico incorporado por la ley de 3 de agosto de 1866,y, unos años después, por su heredera y total deudora, la longeva Ley de Aguas de 13 de junio de 1879, vigente hasta 31 de diciembre de 1985, transcurrido más de un siglo desde que la ley de 18 de diciembre de 1869 extinguiera el Real Patrimonio, poniendo fin, entre otros, a todos los derechos, prestaciones e impuestos relictos que traían origen de la expresada regalía sobre las aguas públicas en los antiguos reinos de Aragón, Mallorca, Valencia y principado de Cataluña, confirmando así la anulación de prestaciones prescrita por las leyes de 19 de julio de 1813 y 4 de febrero de 1837. Las condiciones eran otras, y el contexto también, pero no hay riesgo en afirmar que el dominio público hidráulico trae origen del Real Patrimonio y de la expresada regalía sobre las aguas públicas de los reyes de Aragón, sobre todo en su doble condición de reyes de Valencia.

Como se ha dicho, la gran tradición y rica cultura del agua valencianas, con un reconocimiento de aguas públicas similar al vigente en España hasta 31 de diciembre de 1985, ceñido a aguas epigeas, se proyectaron ampliamente en la ley sobre dominio, uso y aprovechamiento de aguas de 3 de agosto de 1866, que uniformó y unificó el derecho español de aguas. La trayectoria que culminaría en esta norma cuenta con hitos dignos de mención.

Tras la derogación del Estatuto Real de 1834 y el restablecimiento de la Constitución de 1812, bajo la dictadura revolucionaria de Álvarez Mendizábal, la evolución hacia la tradición jurídica valenciana sobre dominio y aprovechamiento del agua se produjo al tiempo que se reemplazaba la autoridad del Patrimonio Real en la materia por la gubernamental. Así, la Real Orden de 22 de noviembre de 1836, reiterada por la de 20 de julio de 1839, otorgó la competencia en policía de aguas a los Jefes Políticos Provinciales; con ello, el Real Patrimonio perdía su tradicional dominio de las aguas públicas. A mayor abundamiento, la Real Orden de 14 de marzo de 1846, con los moderados en el gobierno de la nación, hizo indispensable la autorización regia para cualquier obra o aprovechamiento en los cursos fluviales, es decir, un paso decisivo para la implantación general de la referida tradición jurídica valenciana, con la sustitución indicada, tal y como señala la doctrina de la época, al estimar que la citada disposición «... modifica profundamente la legislación de aguas, las pone de repente en manos de la autoridad suprema y exige que deban obtener previamente la concesión real todos los que quieran, directa o indirectamente, hacer con ellas, en ellas o junto a ellas, cualquier cosa que modifique lo más mínimo su actual estado». Así pues,

6 BRANCHAT, Op. cit., cap. VI, págs. 306-311.

7 BRANCHAT, Op. cit., cap. VI, págs. 336-338. 
como afirma Arrazola, «no basta ya el derecho de propiedad sobre los terrenos riberiegos para usarlas, aprovecharlas ni distribuirlas, ni para hacer en los ríos presa, molino, dique ni puente, ni obra alguna nueva, como sucedía por nuestras antiguas leyes; es preciso atender antes para todo a la resolución del Gobierno que cederá las aguas o permitirá construir en ellas, según sea el objeto de la solicitud y con arreglo a lo que resulte de la previa instrucción de un expediente gubernativo».

El recurso planteado por el Real Patrimonio, en relación con la citada Real Orden de 14 de marzo de 1846, fue desestimado por entero, y la Real Orden de 23 de mayo de 1848 afirmó, entre otros extremos, que el dominio mayor de las aguas corresponde al Estado, $\mathrm{y}$, en el mismo sentido, que la prescripción inmemorial no se aplica a la Justicia mayor, pechos y tributos (Ley IV, Título XXIX, Partida Tercera; Ley IV, Título VIII, Libro IX, Nov. Recop.); dichos fundamentos de derecho fueron reiterados por otra Real Orden de 18 de octubre de 1849, que rechazó el pretendido derecho del Real Patrimonio a imponer cánones por los aprovechamientos de aguas, ya que la antigua facultad de aquél en los reinos de la Corona de Aragón había dejado de corresponderle con la disociación de patrimonio regio y erario público o, en todo caso, fue derogada por las disposiciones abolicionistas de 6 de agosto de 1811 y 26 de agosto de 1837, que disolvieron el régimen señorial. De resaltar es asimismo la importancia de la ley de 24 de junio de 1849 , que reguló la servidumbre de aquae ducendae o paso de aguas, indispensable para el riego de tierras no colindantes con el curso fluvial.

En el planteamiento de la citada norma de 14 de marzo de 1846 insistieron las reales órdenes de 2 de mayo de 1853 y 5 de abril de 1859; la primera calificó los ríos y sus cauces como dominio público, y la segunda reafirmó la exigencia de autorización real para derivar aguas e instalar artefactos movidos por la fuerza hidráulica.

\section{Leyes de 3 de agosto de 1866 , sobre dominio, uso y aprovechamiento de las aguas terrestres y marítimas, y de aguas de 13 de junio de 1879}

Ante la demanda creciente de agua se hizo bien patente la conveniencia de un ordenamiento legal de ámbito nacional, que superase la disparidad territorial del viejo derecho de aguas y contuviese una regulación actualizada y uniforme de las mismas. Con la Unión Liberal en el poder y Leopoldo O’Donnell al frente del gobierno de la nación, un real decreto de 27 de abril de 1859 (Gaceta de Madrid 126, de 6 de mayo), creó una Comisión encargada de redactar un proyecto de ley general de aprovechamiento de aguas.

La exposición de motivos a Isabel II del mencionado decreto de 27 de abril de 1859, la hizo el Ministro de Fomento Rafael de Bustos y Castilla en los términos siguientes: «SEÑNA: Para obtener el mejor aprovechamiento posible de las aguas corrientes que en todas partes, y con especialidad en nuestra Península, es la primera condición de la prosperidad de la agricultura, al mismo tiempo que poderoso auxiliar de los progresos de la industria y del comercio, nada importa tanto si se puede ser tan eficaz como la reforma completa y bien entendida de las disposiciones vigentes en la materia; trabajo delicado, tan indispensable como difícil, cuya necesidad no admite espera, pero que no han logrado realizar todavía de un modo satisfactorio otros países que, reconociendo su urgencia, han hecho esfuerzos por darle cima.

A la multitud de documentos legales que hoy rigen, excesivos por su número, incompletos en su contenido, diseminados entre las demás partes de la legislación patria, contradictorios a veces, con frecuencia confusos, faltos siempre de la unidad como procedentes de diversas épocas y de sistemas de gobierno y de civilizaciones radicalmente distintas, conviene sustituir cuanto antes una ley general que abrace en su conjunto todos los pormenores y 
satisfacer todas las variadas necesidades á que ha de atender la Administración para el fomento de la riqueza pública con el buen empleo de las aguas. Importantes trabajos hay ya reunidos con este objeto en el Ministerio de Fomento, y al estudio del asunto puede ayudar también el proyecto de Código general de aguas presentado al Gobierno por D. Cirilo Franquet, Gobernador que ha sido de varias provincias y Director de Administración Local. Después de allegar a estos antecedentes el dictamen de todas las corporaciones y personas que tienen en el asunto natural competencia, se procederá, si V.M. se digna aprobar el adjunto proyecto de decreto, á la formación de un proyecto de ley redactado con todas las garantías posibles de acierto, y con la brevedad de tiempo que los intereses públicos imperiosamente reclaman».

Seguidamente, un real decreto de 8 de mayo de 1859 designó a los miembros de la Comisión, que, en principio, fueron los siguientes: Don Toribio de Areitio, Inspector de Distrito del Cuerpo de Ingenieros de Caminos, Canales y Puertos; D. Guillermo Schulz, Inspector General primero del Cuerpo de Ingeniero de Minas; D. Agustín Pascual, Ingeniero Jefe de Montes; D. Cirilo Alvarez, Consejero de Estado; D. Cirilo Franquet, Gobernador que ha sido de diferentes provincias; D. Antonio Rodríguez de Cepeda, Decano del Colegio de Abogados de Valencia y Catedrático de Derecho Administrativo de aquella Universidad, y D. Víctor Vergara Moñino; el 24 de agosto del mismo año, se nombró asimismo vocal de la Comisión a D. Manuel Alonso Martínez, ex-ministro de Fomento y diputado a Cortes. Como se ve, en la Comisión eran mayoría los juristas, que asumieron el protagonismo, no sólo porque la aportación de Franquet constituyera el documento de base, sino también por la presencia de Manuel Alonso Martínez y, sobre todo, de Antonio Rodríguez de Cepeda, perfecto conocedor de la administración del agua en tierras valencianas, a quien no puede dejar de relacionarse con la opción por la tradición jurídica valenciana que hizo la Comisión; en la monumental puerta de acceso al Paraninfo de la Universidad de Valencia una lápida recuerda su brillante protagonismo en la redacción de la referida ley.

Siete años mediaron entre el comienzo y final de los trabajos de la Comisión, pero sólo había transcurrido uno desde su nombramiento cuando fue llamada a pronunciarse sobre un asunto de capital importancia, que no admitía demoras, consistente en la jerarquización de usos o aprovechamientos en orden a la concesión de aguas públicas. Se elaboró así el decreto de 29 de abril de 1860 (Gaceta de Madrid no 127, de 6 de mayo), en cuya exposición de motivos, entre otras cosas, se decía: «De la redacción de un código de aguas se está ocupando el Ministerio de mi cargo, auxiliado de la comisión que por decreto de V.M. se creó con ese fin el año anterior (...). Pero sin perjuicio de emplear otros medios protectores, y entre tanto que la ley general de aguas llega a plantearse, es preciso garantir desde luego con reglas fijas los esfuerzos de la especulación individual en esta importante materia, dando seguridades de que serán respetados y atendidos sus derechos y sus intereses.

Conviene que no lleven por ahora más que el carácter de interinas las concesiones que la Administración pública otorgue, pues no puede dárseles el de definitivas hasta que se hallen suficientemente estudiados los ríos de la Península, trabajo difícil y vasto, para el que hay reunido hasta ahora escaso material, y que exigirá mucho tiempo, aun cuando fuese posible dedicar a él todo el personal y todos los recursos que el Gobierno de V.M. tiene precisión de utilizar al mismo tiempo en otras interesantes atenciones. Sin embargo fijándose desde luego el orden de preferencia que ha de regir para los aprovechamientos, podrá ya el interés privado formar su cálculo con cierta seguridad; y, si éstos se apoyan en fundamentos sólidos, adquirir una profunda confianza de ver convertidas en permanentes las concesiones provisionales. Y para los pocos casos en que no haya de ser confirmada, en virtud del plan general de aprovechamientos que se apruebe cuando hayan llegado á su complemento los estudios hidrográficos que deben practicarse con tal objeto, la justicia y 
la conveniencia indican a un mismo tiempo la necesidad de consignar que los empresarios de las obras hechas obtendrán indemnización del costo de éstas, cuando no sea conveniente permitirles en definitiva que sigan utilizando las aguas.

Otra no menos importante garantía se debe ofrecer a los usuarios: la de que los aprovechamientos existentes no serán anulados o perjudicados por otros concedidos con posterioridad. Para establecerla sobre una base sólida se hace preciso practicar el aforo de las aguas en los casos en que las nuevamente concedidas hayan de estar más cerca que las ya utilizadas del nacimiento de las corrientes. No siendo posible por muchas razones, tales como la sequedad del clima, la calidad de las tierras, la mayor o menor permeabilidad del subsuelo, la clase de cultivos y otros, señalar en proporciones exactas la cantidad de agua indispensable para el riego de cada hectárea, habrá necesidad de hacer un estudio especial para casa caso según sus circunstancias peculiares, á fin de que en todas queden cubiertas por completo las necesidades de los riegos inferiores.

(...) estableciendo la preferencia entre las diferentes pretensiones, según la norma de la mayor utilidad pública, generalizando el principio de que la gestión de los asuntos y la decisión de las diferencias pertenezca, dentro de los limites legales, á los mismos interesados y propietarios, por ser éste el sistema más natural, sencillo, justo y acreditado, procurando aprovechar las lecciones de la experiencia ya adquirida en la resolución de las cuestiones de esta clase; mandando regular por medio de módulos la distribución de las aguas á fin de sacar de ellas el mayor partido posible y evitar injusticias en su distribución, estableciendo, en fin, los fundamentos que en su día han de servir para formar un código general sobre esta materia importantísima».

Es de resaltar que este decreto exigía autorización real, en su Art. $1^{\circ}$.1. para el aprovechamiento de las aguas de los ríos, riachuelos, rieras, arroyos u otra clase de corrientes naturales, cualquiera que fuese su denominación. Por su parte, el Art. $5^{\circ}$ estableció en el aprovechamiento de aguas públicas el orden de preferencia siguiente: $1^{\circ}$. Abastecimiento de aguas potables. $2^{\circ}$ Abastecimiento de ferrocarriles. $3^{\circ}$. Riegos. $4^{\circ}$. Canales de navegación y flote. $5^{\circ}$. Movimiento de artefactos. Este es el orden de prioridad que figura asimismo en las leyes de 3 de agosto de 1866 y 13 de junio de 1879. De notar es también, por su estrecha relación con la creación y cometido de las Divisiones Hidrológicas, el contenido del Art. $7^{\circ}$, cuyo tenor es el siguiente: «Siempre que hubiere aprovechamientos inferiores, deberá preceder a la concesión el aforo de las aguas estivales, pudiendo tener lugar tan solo aquella cuando resulte excedente el caudal accesorio después de cubierto con exceso el riego inferior, tomadas en cuenta la calidad y posición de las tierras que este fertilice», y el Art. $8^{\circ}$ precisaba, al respecto, que «no se necesitará, sin embargo, este requisito para hacer concesiones de las aguas invernales y torrenciales que no estuviesen aprovechadas por terrenos inferiores, siempre que la derivación se coloque a la altura competente y se adopten las precauciones necesarias par que no falte el riego que utilicen los antiguos usuarios en las corrientes ordinarias», mientras el artículo 9 añadía: «Los concesionarios de aguas públicas con aplicación al riego tendrán derecho á utilizar la servidumbre forzosa de acueducto establecida por la ley de 24 de junio de 1849 , y en uso de este derecho podrán ejecutar en terreno ajeno y previa indemnización todas las obras necesarias para detener las aguas en el punto de la corriente donde haya de hacerse la derivación y conducirlas á los terrenos regables».

Por su parte, los artículos 14 y 15 preludian la creación de las Divisiones Hidrológicas, que se producirá, un lustro después, con atribuciones específicas a los ingenieros de Caminos, Canales y Puertos, encargados de practicar «un escrupuloso reconocimiento de todos los aprovechamientos existentes que no tuviesen determinada la dotación de agua que han de utilizar, y se fijará la que les corresponda según sus necesidades, estableciendo a costa de los interesados los módulos convenientes». 
A efectos de procedimiento, reviste especial interés el art. 30, último de los contenidos en el Decreto de referencia, cuyo tenor es el siguiente: «La instrucción de los expedientes de aguas públicas se sujetará á los formularios y reglamentos que publicará mi Gobierno para la ejecución del presente decreto. Entre tanto, se observará lo dispuesto en la instrucción general de Obras públicas de 10 de octubre de 1845 y Reales órdenes de 14 de Marzo de 1846, 13 de febrero de 1854 y 20 de abril de 1855»; este trascendental decreto sobre jerarquización de los usos de aguas publicas, sancionado por Isabel II en el denominado gobierno largo de Leopoldo O’Donnell, iba refrendado por el Ministro de Fomento Rafael de Bustos y Castilla. Se inscribe todo ello en el período de notables disposiciones, reales órdenes y decretos, salvo la ley de 24 de junio de 1849, que, desde 1845, dura cuatro lustros y desemboca en la ley de 3 de agosto de 1866 sobre dominio, uso y aprovechamiento de las aguas terrestres y marítimas, vigente hasta la publicación de la de 13 de junio de 1879 , en cuanto a las aguas terrestres, y, por lo que hace a las marítimas, hasta la de Puertos de 7 de mayo de 1880; en una y otra, se refundieron los preceptos correspondientes de aquélla.

Diferenciados en la ley de 3 de agosto de 1866 titularidad estatal de la propiedad y dominio público, la inclusión en éste de las aguas de los ríos, así como las continuas y discontinuas de manantiales, y arroyos que corran por sus cauces naturales, representó un planteamiento distinto al de la legislación europea de aguas, que continuaba admitiendo el derecho del ribereño al aprovechamiento de los cursos de agua, al tiempo que restringía el carácter público de los cursos de agua, a los ríos navegables y flotables. Ello no es, empero, óbice para que la norma contuviese determinados preceptos vinculados a la tradición jurídica castellana; como muestran, primordialmente, los artículos 39 («El derecho á aprovechar indefinidamente las aguas de manantiales y arroyos se adquiere por los dueños de los terrenos inferiores, y en su caso de los colindantes, cuando las hubiesen aplicado sin interrupción por tiempo de 20 años»), 225 («Los dueños de predios contiguos a vías públicas podrán recoger las aguas pluviales que por ellas discurran y aprovecharlas en el riego de sus predios (...)»), 226 («Los dueños de los predios lindantes con cauces públicos de rieras, ramblas o barrancos, pueden aprovechar en su regadío las aguas pluviales que por ellos discurran, construyendo al efecto, sin necesidad de autorización, malecones de tierra y piedras sueltas o presas móviles o automóviles»), 233 («En los ríos navegables, los ribereños podrán en sus respectivas riberas establecer libremente norias, bombas o cualquier otro artificio destinado a extraer las aguas necesarias para el riego de sus propiedades limítrofes, siempre que no causen perjuicio a la navegación. En los demás ríos públicos será necesaria la autorización del Gobernador de la provincia (...)»), 259 («En los ríos no navegables ni flotables, los dueños de ambas riberas podrán establecer barcas de paso o puentes de madera destinados al servicio público, previa la autorización del Alcalde, quien fijara las tarifas y las condiciones necesarias para que su construcción, colocación y servicio ofrezcan a los transeúntes la debida seguridad.»), 263 («En los ríos no navegables ni flotables, el que fuese dueño de ambas riberas puede libremente establecer cualquier artificio, maquinaria o industria. Siendo solamente dueño de una ribera, no podrá pasar del medio del cauce. En uno y otro caso deberá plantear el establecimiento sin perjuicio de los predios limítrofes ni los regadíos, y sin peligro para las industrias interiormente situadas.») y 264 («La autorización pura establecer en los ríos navegables o flotables cualesquiera aparatos o mecanismos flotantes haya o no de transmitir el movimiento a otros fijos ni la ribera, se concederá por el Gobernador, previa la instrucción de expediente en que se oiga a los dueños de una ribera y otra y a los de los establecimientos industriales inmediatamente inferiores, acreditándose además las circunstancias siguientes: $1^{\circ}$. Ser el solicitante dueño de la ribera donde deban amarrarse las barcas para el proyectado establecimiento o haber obtenido permiso de quien lo sea (...)»). 
A diferencia de las aguas vivas y corrientes, adscritas casi por entero al dominio público, no ocurrió otro tanto, a pesar del empeño de Cirilo Fontanet, con las subterráneas, como evidencian los artículos siguientes: 45 («Pertenecen al dueño de un predio en plena propiedad las aguas subterráneas que en él hubiese obtenido por medio de pozos ordinarios, cualquiera que sea el aparato empleado para extraerlas»), 46 («Todo propietario puede abrir libremente pozos y establecer artificios para elevar aguas dentro de sus fincas, aunque con ello resultasen amenguadas las aguas de sus vecinos. Deberá sin embargo guardarse la distancia de dos metros entre pozo y pozo dentro de las poblaciones y de 15 metros en el campo, entre la nueva excavación y los pozos, estanques, fuentes y acequias permanentes de los vecinos»), 46 («Cuando se buscare al alumbramiento de aguas subterráneas por medio de pozos artesianos o por socavones o galerías, el que las hallase o hiciese surgir a la superficie del terreno será el dueño de ellas a perpetuidad, sin perder su derecho aunque salgan de la finca donde vieron la luz, cualquiera que sea la dirección que el alumbrador quiera darles en todo tiempo. Si el dueño de las aguas alumbradas no construyese acueducto para ellas en los predios inferiores que atraviesen sino que las dejase abandonadas a su curso natural, entonces entrarán los dueños de estos predios a disfrutar del derecho eventual que les confiere el artículo 34 respecto de los manantiales naturales superiores») y 49 («El dueño de cualquier terreno puede alumbrar y apropiarse plenamente por medio de pozos artesianos y por socavones o galerías las aguas que existen debajo de la superficie de su finca, con tal que no distraiga o aparte aguas públicas de su corriente natural. Por regla general, cuando amenazase el peligro inminente de que un pozo artesiano o un socavón o galería distraiga o merme las aguas de una fuente o de una corriente destinadas al abastecimiento de una población o riegos existentes, se suspenderán las obras siempre que fuesen denunciadas por el Ayuntamiento o por la mayoría de los regantes. Si del reconocimiento por dos peritos nombrados por las partes y tercero en discordia, según el derecho común, resultare existir el peligro inminente, no podrán continuarse las labores, sino que se declarará por el Gobierno anulada la concesión»).

Como se ha dicho, no prosperó en la Comisión la iniciativa de Franquet para equiparar, a efectos de titularidad, las extracciones de aguas subterráneas a las explotaciones mineras. Es de notar que, mediado el siglo XIX. la importancia de los recursos hipogeos, aunque capital para las áreas beneficiadas, resultaba, en conjunto, relativamente modesta, ya que, además de galerías drenantes tipo foggara, pozos artesianos, pantallas o presas subálveas, cimbres y minados, que proporcionaban aguas caballeras, las elevaciones se conseguían esencialmente con el empleo de norias de sangre o tracción animal, molinos de viento y las primeras bombas centrífugas, en número reducido, accionadas por vapor.

La aplicación de la ley 3 de agosto de 1866 sobre dominio, uso y aprovechamiento de las aguas terrestres y marítimas y su régimen y policía durante el convulso y proceloso sexenio revolucionario no estuvo exenta de dificultad, al punto que el Gobierno de la República resolvió explicitarla mediante un reglamento; para redactarlo, el Decreto de 5 de abril de 1873 designó la Comisión correspondiente. Los trabajos do la Comisión se prolongaron seis años, y no proporcionaron el reglamento previsto en principio, sino un texto refundido de la propia norma, es decir, la Ley de Aguas de 13 de junio de 1879, vigente por más de un siglo, hasta 31 de diciembre de 1985.

Contempladas las aguas marinas en la Ley de Puertos de 7 de mayo de 1880, la Ley de 13 de junio de 1879 se refiere exclusivamente a las aguas terrestres o continentales. Cumplió así la citada Comisión el encargo, que le fue confiado por el Real Decreto de 22 de enero de 1874, de formular un proyecto de Ley de Aguas revisando y unificando la parte vigente de la de 1866, en armonía con las demás disposiciones legales que con ella se relacionan, principalmente con el decreto-ley de 14 de noviembre de 1868 que había anulado varios 
de sus artículos, y con la ley especial de Canales de riego de 20 de febrero de 1870, que dejó sin aplicación algunos otros. Así pues, la Ley de Aguas de 13 de junio de 1879 es un texto refundido de la de 3 de agosto de 1866, con la cual, bajo distinta numeración, se corresponden y concuerdan la gran mayoría de los artículos de aquélla, transcritos en su integridad o modificados ligeramente algunos de ellos; así, los números 93 y 101 se reproducen como 55 y 61 de la ley de 1879 con la sola modificación de atribuir al Ministro de Fomento las facultades que la de 1866 confería a los gobernadores. La diferencia más notoria entre ambas normas es la supresión en la de 1879 do los artículos de la de 1866 derogados por el decreto-ley de 14 de noviembre de 1868, que conciernen primordialmente a obras de defensa contra las aguas públicas $(93,94,95$ y 98), desecación de lagunas y terrenos pantanosos $(101,102$, segunda parte del 106 y 108) y aprovechamiento de aguas públicas para abastecimiento a poblaciones (217 y 218); hagamos notar que, a pesar de la derogación indicada, los artículos 93, 101, 217 y 218 fueron reproducidos con los números $55,61,169$ y 170 de la ley de 13 de junio de 1879 .

A la referida Ley de 13 de junio de 1879 hay que añadir, en el último tercio del siglo XIX, las encaminadas a incentivar obras hidráulicas en régimen de concesión, objetivo común de las leyes de 20 de febrero de 1870 y 27 de julio de 1883. que derogó a la anterior; es de resaltar que mientras la primera se refiere única y exclusivamente a la realización de canales de riego, la segunda regula los auxilios a la construcción de canales y pantanos de interés público, marcando un punto de inflexión en la polémica de los embalses, cambio de rumbo confirmado por la ejecución entre 1881 y 1885, en régimen de concesión, de la tercera presa de Puentes.

\section{Ley de aguas de 1985: el agua, recurso unitario de dominio público estatal}

La Ley 29/1985, de 2 de agosto, de Aguas reemplazó a la longeva y más que centenaria Ley de Aguas de 13 de junio de 1879, vigente hasta 31 de diciembre de 1985. Esta última norma, heredera directa y, en aguas continentales, universal de la Ley sobre dominio y aprovechamiento de agua de 3 de agosto de 1866, primer código español y europeo de la materia, con muchos de sus artículos transcritos literalmente o incorporados sin apenas variación, fue, justa y generalmente, considerada texto jurídico modélico y auténtica compilación; y por ello durante un tiempo más que prudencial, se prefirió actualizarla y complementarla a sustituirla. Sin embargo, esto no bastó para evitar su obsolescencia, ya que, transcurrido un siglo de profundas mudanzas, la situación de los recursos hídricos en España resultaba bien diferente a la regulada originariamente.

Las causas primordiales del desfase eran varias, y todas ellas de gran trascendencia. Entre ellas, las siguientes: en hidrología, la distinción radical entre aguas epigeas y subterráneas contenida en la referida ley había dejado paso al reconocimiento incuestionable de la unidad del ciclo hidrológico; y, en este orden de cosas, el derecho de libre apropiación de los caudales hipogeos alumbrados, así como la propiedad particular de las aguas vivas o perennes de ríos-ramblas alicantinos, murcianos y almerienses chocaba con el instituto del dominio público hidráulico; además, la demanda de agua había crecido de modo exponencial, en particular para riego y abastecimiento urbano; y, en íntima relación con ese incremento, durante el novecientos, sobre todo en su segunda mitad, las aguas fluviales que, en 1901, eran casi enteramente fluyentes, con una capacidad total de embalse que no llegaba a $100 \mathrm{hm}^{3}$, se habían transformado en reguladas, y aquélla se había elevado a $55.000 \mathrm{hm}^{3}$. Tampoco los usos del agua eran ya los contemplados, sucesivamente, en el Real Decreto de 29 de abril de 1860, Ley de 3 de agosto de 1866 y Ley de 13 de junio de 1879 (abastecimiento a poblaciones, suministro a ferrocarriles, riegos, canales de navega- 
ción, molinos y otras fábricas, barcas de paso, puentes flotantes y estanques para viveros o criaderos de peces): unos (abastecimiento a ferrocarriles, flotación de maderas, barcas de paso y puentes flotantes) se habían extinguido o perdido mucha importancia (canales de navegación), mientras surgieron otros nuevos (aprovechamiento hidroeléctrico, usos recreativos). Por su parte, el empleo de aguas subterráneas, puntual y relativamente poco significativo al promulgarse la Ley, se multiplicó y adquirió gran relevancia en la segunda mitad del siglo XX.

Y por último, el recurso se vió seriamente afectado por procesos varios y muy graves de contaminación, problema éste de muy reducido alcance en las postrimerías del ochocientos. En efecto, determinados consumos y usos de agua desembocaron en abusos, convirtiéndola de recurso en desecho, no sólo a causa del fortísimo crecimiento de la demanda, sino de diversos y severos procesos de contaminación, con frecuencia acumulados. Se produjo, también, a partir de los años sesenta de la centuria precedente, una movilización masiva e ingente de aguas subterráneas, y han menudeado los bombeos excesivos, con casos flagrantes de sobreexplotación, traducidos en descensos espectaculares de niveles piezométricos y perforaciones y, sobre todo, deterioro de los acuíferos, salinizados los costeros por intrusión marina y disolución del Keuper salífero algunos del interior; en el menoscabo de las aguas hipogeas cuenta asimismo la utilización excesiva de abonos minerales y productos fitosanitarios, así como el almacenamiento y vertido en las inmediaciones de los freáticos de sustancias contaminantes de todo tipo. No constituye exageración alguna afirmar que los recursos ambientales, con el agua en primer término, han padecido, en la segunda parte del novecientos, una agresión intensa y muy preocupante, pareja al enorme potencial de los procesos químicos, físicos y mecánicos lesivos para el medio desencadenado por el hombre; así pues, la necesidad de proteger a los recursos hídricos resultaba inaplazable.

Y a todos estos factores vino a sumarse la promulgación de la Constitución de 1978, con la creación del llamado Estado de las Autonomías; se convirtió así en apremio contar con una nueva Ley de Aguas, que sería sancionada por el Rey y refrendada por el presidente del Gobierno el 2 de agosto de 1985. El preámbulo de la misma se refería, a los susodichos hechos, de esta forma: «Por su parte, la vigente Ley de Aguas, de 13 de junio de 1879 , modelo en su género y en su tiempo, no puede dar respuesta a los requerimientos que suscitan la nueva organización territorial del Estado, nacida de la Constitución de 1978, las profundas transformaciones experimentadas por la sociedad, los adelantos tecnológicos, la presión de la demanda y la creciente conciencia ecológica y de mejora de la calidad de vida. Buena prueba de ello es la fronda legislativa que ha sido promulgada hasta la fecha, con variado rango normativo, en un intento, a veces infructuoso, de acomodarse a las cambiantes circunstancias socio-económicas, culturales, políticas, geográficas e, incluso, de supervivencia, como en los casos puntuales de sobreexplotación o grave contaminación de acuíferos.

Se hace, pues, imprescindible una nueva legislación en la materia, que aproveche al máximo los indudables aciertos de la legislación precedente y contemple tradicionales instituciones para regulación de los derechos de los regantes, de las que es ejemplo el Tribunal de las Aguas de la Vega Valenciana, pero que tenga muy en cuenta las transformaciones señaladas, y, de manera especial, la nueva configuración autonómica del Estado, para que el ejercicio de las competencias de las distintas Administraciones se produzca en el obligado marco de colaboración, de forma que se logre una utilización racional y una protección adecuada del recurso».

Durante tres lustros, hasta su modificación por la Ley 46/1999, de 13 de diciembre, que incorporó algunas otras, las referencias esenciales de la Ley 29/1985 fueron: institución del dominio público hidráulico, control, mantenimiento y adecuación del mismo, gestión 
de la calidad de las aguas continentales, planificación hidrológica y coordinación en esta materia de las distintas Administraciones Públicas. Sus ocho títulos concernían, respectivamente, a las cuestiones siguientes: dominio público hidráulico del Estado; administración pública del agua, planificación hidrológica, utilización del dominio público hidráulico, protección del dominio público hidráulico y de la calidad de las aguas continentales, régimen económico-financiero de la utilización del dominio público hidráulico, infracciones, sanciones y competencias de los tribunales, y obras hidráulicas. Incluía, además, el título preliminar, nueve disposiciones transitorias, ocho adicionales y cuatro finales. Por último, la disposición derogatoria 1 afectaba a las disposiciones siguientes: Ley de Aguas de 13 de junio de 1879; los artículos 407 a 425 del Código Civil de 24 de julio de 1889 en cuanto se opusiesen a la nueva Ley; Ley de 24 de julio de 1918 sobre desecación de lagunas, marismas y terrenos pantanosos; Real Decreto-Ley de 19 de julio de 1927, por el que se modificaba el artículo 1 de la Ley anterior; Ley de 20 de mayo de 1932 sobre atribución a los Jefes de obras públicas de facultades de los Gobernadores Civiles y el artículo 38.5 de la Ley de Montes de 8 de junio de 1957. Por su parte, la disposición derogatoria 2 declaraba derogadas las demás disposiciones de carácter general que se opusiesen a la Ley, salvo en la Comunidad Autónoma de Canarias, donde subsistiría la legislación que se aplicaba en dicho territorio hasta tanto aquélla no dictase otras normas; finalmente, la disposición derogatoria 3 establecía que el Gobierno, antes de la entrada en vigor de la Ley 29/1985, completaría, mediante Real-Decreto la tabla de vigencias de las disposiciones afectadas por la nueva Ley de Aguas.

Sentado el principio, científicamente indiscutido, de la unidad del ciclo hidrológico, consecuencia jurídica obligada de la misma era la generalización del dominio público hidráulico de las aguas continentales, con incorporación al mismo de las subterráneas, cuya titularidad la Ley de Aguas de 13 de junio de 1879 atribuía a quien las alumbrase, otorgándole el derecho de apropiárselas. Así pues, el Art. 1.2 de la Ley 29/1985 declaró la demanialidad de las aguas continentales, incluyendo junto a las epigeas las subterráneas renovables, de manera que, al constituir un recurso unitario, quedasen todas ellas supeditadas al interés general; a pesar de dúo, la norma no reguló las aguas termales o minerales, contempladas en la Ley de Minas.

La demanialidad venía exigida por la propia unidad del ciclo hidrológico, y, ante el rápido incremento de la demanda de agua, abonada por la necesidad de prevenir y evitar el aprovechamiento anárquico de los recursos hídricos, la sobreexplotación y salinización de acuíferos. y la conversión de los primeros en desecho por los procesos de contaminación. Dicha declaración de demanialidad invocaba los artículos 45.2, 128, 131 y 132.2 de la Constitución; y, para no entrar en conflicto abierto y flagrante con el 33.3 de la misma, las disposiciones transitorias atemperaron el alcance expropiatorio de la norma. (Disposiciones transitorias $\left.1^{\mathrm{a}} \cdot 1,2^{\mathrm{a}} \cdot 1,3^{\mathrm{a}} \cdot 1^{\mathrm{o}}, 3^{\mathrm{a}} \cdot 2,4^{\mathrm{a}} \cdot 1,4^{\mathrm{a}} \cdot 3\right)$.

Por supuesto, no faltó la controversia: mientras algunos autores consideraron que se producía una pérdida o, cuando menos, mutación del derecho de propiedad, otros estimaron que más bien se operaba una limitación de la misma. Obviamente, el propósito del derecho transitorio obedecía, mucho más que a una preocupación por la seguridad jurídica de los propietarios de aguas, al propósito de no acudir a la vía expropiatoria, que habría supuesto un proceso de enorme amplitud y costosísimo para la Administración, y de esquivar, al propio tiempo, los previsibles recursos y cuestiones de inconstitucionalidad ${ }^{8}$.

Además de la extensión de la demanialidad a todas las aguas continentales, decisión cuya trascendencia jurídica y económica resulta innecesario encarecer, otros asuntos

8 Sentencia del Tribunal Supremo (Sala de lo Civil), 20 de julio de 2004 (RJ 2004/4450). 
esenciales abordados por la Ley 29/1985, de Aguas, fueron la planificación hidrológica, mantenimiento y adecuación del dominio público hidráulico, gestión de la calidad de las aguas y coordinación de las distintas administraciones públicas con competencias sobre aguas continentales. La norma contempló, en sus múltiples aspectos, dicha materia, cuya realidad era bien distinta a la existente un siglo antes; la regulación se hizo por medio de Títulos concernientes, respectivamente, a dominio público hidráulico, administración del agua, planificación hidrológica, utilización y protección del dominio público hidráulico y de la calidad de las aguas, régimen económico-financiero de la utilización del dominio público hidráulico, infracciones, sanciones, competencias de los tribunales, y obras hidráulicas.

\section{Las aguas desalinizadas en el dominio público hidráulico del Estado}

Como se ha dicho la ley 29/1985, de 2 de agosto, de Aguas incluyó las aguas desalinizadas en el dominio público del Estado, al declarar, en su art. $2^{\circ}$.e, que, además de otras, constituían el expresado dominio «las aguas procedentes de la desalación de agua de mar una vez que fuera de la planta de producción, se incorporen a cualquiera de los elementos señalados en los apartados anteriores»; los elementos aludidos en los cuatro apartados precedentes del indicado artículo eran aguas continentales, cauces de corrientes naturales, lechos de lagos, lagunas, y de embalses superficiales en cauces públicos, y acuíferos subterráneos. Así pues, las aguas desalinizadas, al incorporarse a los elementos que constituían el dominio público hidráulico del Estado, pasaban a formar parte de éste.

A diferencia de lo ocurrido con la más que centenaria Ley de Aguas de 13 de Junio de 1879, no transcurrieron tres lustros sin que la 29/1985, de 2 de agosto, experimentase sustanciales modificaciones, relativas, sobre todo, a incremento de recursos no convencionales, cesión de derechos a usos privativos del agua y políticas de ahorro de la misma. En la Exposición de Motivos de la Ley 46/1999, de 13 de diciembre, figuran, entre otros, los párrafos siguientes: «...la experiencia de la intensísima sequía padecida por nuestro país en los primeros años de la década final de este siglo, imponen la búsqueda de soluciones alternativas que, con independencia de la mejor asignación de recursos disponibles a través de mecanismos de planificación, permitan, de un lado, incrementar la producción de agua mediante la utilización de nuevas tecnologías, otorgando rango legal al régimen jurídico de los procedimientos de desalación o reutilización; de otro, potenciar la eficiencia en el empleo de agua, para lo que es necesario la requerida flexibilización del actual régimen concesional a través de la introducción del nuevo contrato de cesión de derechos de agua, que permitirá optimizar socialmente los usos de un recurso tan escaso, y, por último, introducir políticas de ahorro de agua, bien estableciendo la obligación general de medir los consumos mediante sistemas homologados de control o por medio de la fijación administrativa de consumos de referencia para los regadíos.

Asimismo, las mayores exigencias que imponen, tanto la normativa europea como la propia sensibilidad de la sociedad española, demandan de la Administración Pública la articulación de mecanismos jurídicos idóneos que garanticen el buen estado ecológico de los bienes que integran el dominio público hidráulico, a través de instrumentos diversos, como pueden ser, entre otros, el establecimiento de una regulación mucho más estricta de las autorizaciones de vertido, para que éstas puedan constituir verdaderamente un instrumento eficaz en la lucha contra la contaminación de las aguas continentales, o la regulación de los caudales ecológicos como restricción general a todos los sistemas de explotación» ${ }^{9}$.

9 Ley 46/1999, de 13 de diciembre (BOE n ${ }^{\circ} 298$, del 14 de diciembre). 
Con las finalidades indicadas, entre otras adiciones y modificaciones a la Ley de Aguas de 2 de agosto de 1985, se añadió el Capítulo V del Título Primero, concerniente a aguas procedentes de desalación, se dió nueva redacción al art. 101, sobre reutilización de aguas depuradas, y se introdujo el extenso art. 61 bis, que contempló dos fórmulas diferentes para la cesión de derechos al uso privativo de las aguas.

A los efectos que ahora interesan, el expresado Capítulo V del Título Primero constaba del art. 12 bis, asimismo de nueva creación por la ley 46/1999. El tenor del referido precepto era el siguiente: «Cualquier persona física o jurídica podrá realizar la actividad de desalación de agua de mar, previas las correspondientes autorizaciones administrativas respecto de los vertidos que procedan, a las condiciones de incorporación al dominio público hidráulico y a los requisitos de calidad según los usos a los que se destine el agua.

2. Lo dispuesto en este artículo se entiende sin perjuicio de las autorizaciones y concesiones demaniales que sean precisas de acuerdo con la Ley 22/1988, de 28 de julio, de Costas, y las demás que procedan conforme a la legislación sectorial aplicable si a la actividad de desalación se asocian otras actividades industriales reguladas, así como las derivadas de los actos de intervención y uso del suelo.

Aquellas autorizaciones y concesiones que deban otorgarse por dos o más órganos u organismos públicos de la Administración General del Estado se tramitarán en un solo expediente, en la forma que reglamentariamente se determine.

3. La desalación de aguas continentales se someterá al régimen previsto en esta Ley para la explotación del dominio público hidráulico».

En suma, la ley 46/1999 fue enteramente respetuosa con la regulación demanial de las aguas desaladas contenida en la Ley 26/1985; y, precisamente el art. 12 bis.1 aprovechó el margen de incorporación al dominio público hidráulico establecido en el Art. 2.6 para invitar a la iniciativa privada a participar en dicha actividad, haciendo patente esta posibilidad, cuyo automatismo extinguió la ley 11/2005, de 22 de junio, que modificó la ley 10/2001, de 5 de julio, del Plan Hidrológico Nacional ${ }^{10}$. Aquella norma amplió los contenidos del Real Decreto Ley 2/2004, que motivó la paralización de las obras de la transferencia del Ebro, reproduciendo la misma exposición de motivos, pero añadiendo nuevas modificaciones a la Ley del Plan Hidrológico Nacional y al propio Texto Refundido de la Ley de Aguas (RD. 1/2011, de 20 de julio). En efecto, a través de su disposición final primera, la ley 11/2005 modificó el art. 2.e de la Ley de Aguas, sustituyendo la redacción originaria («Las aguas procedentes de la desalación de agua de mar una vez que, fuera de la planta de producción, se incorporen a cualquiera de los elementos señalados en los apartados anteriores») por otra («Las aguas procedentes de la desalación de agua de mar»), cambio que implicaba la anticipación de la demanialidad al propio origen del proceso, con la subsiguiente exigencia de disposición legal o concesión administrativa, y el control político de las mismas, dejando sin efecto el Capítulo V del Título I, añadido por la Ley 46/1999, de 13 de diciembre (BOE $n^{\circ} 298$, del 14).

Entre la promulgación de la Ley sobre dominio, uso y aprovechamiento de aguas, de 3 de agosto de 1866, y la de la Ley 11/2055, de reforma de la Ley 10/2001, del Plan Hidrológico Nacional, transcurre casi siglo y medio, periodo en que el dominio público hidráulico conoce una diacronía que amplía su contenido, y asimismo sus motivaciones o fundamentos. Las susodichas modificaciones fueron introducidas por la Ley 29/1985, de Aguas, que derogó y reemplazó a la más que centenaria Ley de Aguas de 13 de junio de 1879. El articulado de la nueva norma desarrolló y preceptuó los principios básicos

10 Ley 11/2005, de 22 de junio, por la que se modifica la Ley 10/2001, de 5 de julio, del Plan Hidrológico Nacional (BOE n 149 , del 23, págs. 21853-21854). 
enunciados en su preámbulo, donde, entre otros extremos, se resaltaba «...la necesidad de que los instrumentos jurídicos regulen, actualizadas, las instituciones necesarias, sobre la base de la imprescindible planificación hidrológica y el reconocimiento, para el recurso, de una sola calificación jurídica, como bien de dominio público estatal, a fin de garantizar en todo caso su tratamiento unitario, cualquiera que sea su origen inmediato, superficial o subterráneo. Este planteamiento impone, por tanto, como novedad la inclusión en el dominio público de las aguas subterráneas, desapareciendo el derecho a apropiárselas que concedía la Ley de 1879 a quien las alumbrase...

Por otra parte, la vigente Ley de Aguas, de 13 de junio de 1879, modelo en su género y en su tiempo, no puede dar respuesta a los requerimientos que suscitan la nueva organización territorial del Estado,..., las profundas transformaciones experimentadas por la sociedad, los adelantos tecnológicos, la presión de la demanda y la creciente conciencia ecológica y de mejora de la calidad de vida. Buena prueba de ellos es la fronda legislativa que ha sido promulgada hasta la fecha..., en un intento, a veces infructuoso, de acomodarse a las cambiantes circunstancias socio-económicas, culturales, políticas, geográficas e, incluso, de supervivencia, como en los casos puntuales de sobreexplotación o grave contaminación de acuíferos.

Se hace, pues, imprescindible una nueva legislación en la materia...»

Entre otras referencias, la Ley 29/1985, de 2 de agosto, de Aguas, dedicó, además de su Título Preliminar, el Título I al dominio público hidráulico del Estado, el IV a la utilización del dominio público hidráulico, el V a la protección del dominio público hidráulico y calidad de las aguas continentales y el VI al régimen económico-financiero de la utilización del dominio público hidráulico; unos meses después, el Real Decreto 849/1986, de 11 de abril, aprobó el Reglamento de Dominio Público Hidráulico, ya modificado, al igual que la propia Ley de Aguas y su Texto Refundido. 
